Reseña

\section{Miguel Suárez Bosa. Le Port de Casablanca au xxe siècle. Une source de développement pour le Maroc. Paris, Editions L'Harmattan, 2019, 240 pp. ISBN: 978-2343178028.}

El profesor Miguel Suárez Bosa, experto en historia marítima y portuaria, analiza en este libro la situación del puerto de Casablanca durante la etapa del Protectorado francés de Marruecos, situada concretamente entre 1912 y 1956. El libro publicado es buena muestra de la internacionalización de la universidad española en general y de la de Las Palmas de Gran Canaria en particular. El autor es catedrático de Historia e Instituciones Económicas de la citada universidad y en su recorrido como investigador se ha especializado en historia portuaria y su importancia en el desarrollo económico de los diferentes estados. A partir del análisis del Puerto de La Luz y de Las Palmas como estación carbonera en el siglo xIX, su mirada se reorienta posteriormente hacia la vecina costa africana y al Atlántico más meridional.

El trabajo que reseñamos podría considerarse un estudio de caso que integra el análisis de las variables características de los puertos modernos tras la reforma portuaria iniciada a mediados del siglo xIx. Las nuevas tecnologías aplicadas a la navegación en la Segunda Revolución Industrial (hélices, cascos de acero, calderas de vapor más eficientes y, más adelante, combustibles líquidos) permitirán la construcción de grandes buques que exigen infraestructuras portuarias adaptadas a su tamaño y circunstancias, que fueran capaces de darles cabida y garantizar una correcta gestión operativa. En su intento por competir con otros puertos de la región, como el británico de Gibraltar o el de la ciudad libre de Tánger, las autoridades del Protectorado apostaron por la construcción de un puerto que tuviera un carácter nacional, empleando en él los últimos avances técnicos. Según el autor del trabajo, el puerto tendría que ser capaz de asumir la función de motor vertebrador de la economía del país mediante el desarrollo de su conectividad con otros medios de transporte, la red ferroviaria y la red vial, en unión de otras infraestructuras que propiciaran la movilización de recursos económicos y el crecimiento del comercio exterior.

El libro se organiza en dos grandes bloques. Los cuatro primeros capítulos contienen un planteamiento metodológico y un ejercicio de contextualización histórica a partir de las diversas teorías relativas al desarrollo económico en general y las referentes al análisis portuario en especial. Los Acuerdos de Algeciras (1906) y el Tratado de Fez (1912) se constituyen como pilares forjadores del marco institucional en el que se inserta la historia del Protectorado francés de Marruecos y la elección del puerto de Casablanca como motor del cambio de una economía tradicional a una economía moderna. En la segunda parte del libro se asiste al análisis del puerto de Casablanca en concreto y a su fructífera relación con la ciudad, extendiéndo- se más allá del propio entorno portuario hasta la red de puertos secundarios (Casablanca como centro de una red jerarquizada), a su propia región, al resto de Marruecos y hasta su proyección atlántica controlada desde la potencia colonial. El libro se cierra con una mirada a la situación de Marruecos a partir del momento de la independencia (1956), desde la ventana privilegiada del propio puerto de Casablanca. Se nos frece una visión crítica en la que se reconocen los fallos estructurales ocurridos durante el período colonial, pero anotando al mismo tiempo los avances realizados y los éxitos alcanzados en el desarrollo hacia la formación de una economía moderna.

El Estado francés, acorde con su estatus de potencia administradora y responsable en última instancia de la administración del territorio marroquí asignado en el Tratado de Fez de 30 de marzo de 1912, decidió invertir en bienes de capital e infraestructura de comunicación, asignando la mitad del presupuesto del período 1914-1920 a los sectores portuario, vial y ferroviario. Esta política se basaba en la convicción de las autoridades del Protectorado de la importancia de proporcionar al país infraestructuras públicas o público-privadas para estimular el crecimiento económico y el desarrollo nacional. En consecuencia, la voluntad política impulsó la colaboración con ambos sectores desde dos enfoques: inversión de fondos públicos en empresas mixtas, como la Manutention Marocaine, responsable gestión de la actividad laboral y portuaria; y financiación de empresas públicas como la Office chérifien des phosphates, entidad responsable de la explotación y gestión de los ricos depósitos de fosfatos y beneficiaria de la concesión de actividades portuarias relacionadas con el envío al exterior de esta materia prima.

Ciertamente, la decisión de instalar y construir un gran puerto en Casablanca constituyó un desafío técnico considerable dadas las dificultades adversas que presentaba el litoral atlántico marroquí. En ese sentido, el desarrollo de los trabajos se convertiría muy pronto en campo de pruebas para una serie de novedosas técnicas de construcción que debían ser aplicadas en condiciones naturales poco favorables. La infraestructura final sería el resultado de la voluntad política del Protectorado francés para construir ese gran puerto nacional y de destinar a esa misión buena parte de la inversión pública prevista.

La investigación que reseñamos aborda asimismo otros aspectos sociales y políticos relacionados con el territorio de Marruecos. Casablanca representa la puerta principal de entrada y salida de una economía que, cuando se construye el puerto, aparece atrasada, tradicional y organizada en torno a un marco institucional prácticamente de carácter feudal. Por eso, la construcción del puerto impulsa el desarrollo de una gran ciudad industrial y comercial para convertirse en el motor del desarrollo del país. La obra bascula entre esos dos ejes, el puerto y la ciudad de Casablanca, para explicarnos la simbiosis 
entre los polos que van a convertirse en clave de la nueva era económica, política y social que surge con el establecimiento del Protectorado. En este sentido, cabe destacar la estructura sectorial dual que se constituye como una característica fundamental del sistema económico y social marroquí. Se trata de una economía basada, por un lado, en un sector tradicionalmente vinculado a la agricultura y la cría de ganado que apenas promueve la innovación; por otro, dispone de un dinámico sector de exportación vinculado a los productos mineros, agrícolas e industriales. Este último sector fue el que atrajo mayormente la atención de las autoridades del Protectorado, que apenas se preocuparon por el desarrollo o la financiación de otras infraestructuras educativas y cualquier forma de progreso social, pues el modelo económico elegido no requería de mano de obra con un alto nivel de educación. Sí se necesitaban, no obstante, trabajadores que gozaran de buena salud, lo que ejerce su influencia sobre otros ámbitos relacionados con la sanidad.

En definitiva, Suárez Bosa nos entrega una obra de gran utilidad que se cierra además con una serie de reflexiones sobre el horizonte que deben abarcar las futuras investigaciones sobre el sector, un análisis de las fuentes estadísticas y sus posibilidades de análisis, además de un útil y adecuado glosario de términos. Así, pues, este tipo de trabajos constituye un buen ejemplo de la internacionalización de la investigación y de las ganancias sobre el desarrollo que de esta amplitud de perspectivas pueden derivarse.

Sergio Solbes Ferri

Universidad de Las Palmas de Gran Canaria 